\title{
Critical Differences Between Dietary Supplement and Prescription Omega-3 Fatty Acids: A Narrative Review
}

\author{
Daniel E. Hilleman - Barbara S. Wiggins - Michael B. Bottorff
}

Received: October 4, 2019 / Published online: January 9, 2020

(C) The Author(s) 2020

\begin{abstract}
Introduction: Currently available omega-3 (OM-3) fatty acid products in the US are either nonprescription dietary supplements (e.g., fish oils) or prescription (Rx) medications. As such, we aimed to describe critical therapeutic differences among the OM-3 fatty acids, focusing on differences between fish oil supplements and $\mathrm{Rx}$ OM-3s.

Methods: A narrative review of known papers salient to this topic was conducted.

Results: Despite the multiple purported clinical benefits, the published evidence for OM-3 dietary supplements is generally insufficient, inconsistent, or negative. Rx OM-3 products are indicated as an adjunct to diet to reduce triglycerides (TG) in adults with severe hypertriglyceridemia (TG $\geq 500 \mathrm{mg} / \mathrm{dl})$. Recently, the
\end{abstract}

Enhanced Digital Features To view enhanced digital features for this article go to https://doi.org/10.6084/ m9.figshare.11381118.

D. E. Hilleman ( $₫)$

School of Pharmacy and Health Professions,

Creighton University, Omaha, NE, USA

e-mail: danielhilleman@creighton.edu

B. S. Wiggins

Medical University of South Carolina, Charleston, SC, USA

M. B. Bottorff

Department of Pharmacy Practice, Manchester

University, Fort Wayne, IN, USA
Rx eicosapentaenoic acid (EPA)-only OM-3, icosapent ethyl, demonstrated cardiovascular $(\mathrm{CV})$ risk reduction among statin-treated patients at high risk of $\mathrm{CV}$ disease in a large $\mathrm{CV}$ outcomes trial (CVOT), and is now also indicated as an adjunct to maximally tolerated statin therapy to reduce the risk of myocardial infarction, stroke, coronary revascularization, and unstable angina requiring hospitalization in adult patients with elevated TG ( $\geq 150 \mathrm{mg}$ / $\mathrm{dL}$ ) and established CVD or diabetes mellitus and $\geq 2$ additional risk factors for CVD. In contrast to the rigorous regulatory standards for safety, efficacy, and manufacturing of medications (whether Rx or over the counter), the Food and Drug Administration manages dietary supplements as food. Issues specific to OM-3 dietary supplements include variable content, labeling inconsistencies, and poor product quality/impurity. Given these issues, OM-3 dietary supplements should not be substituted for Rx OM-3 products. The efficacy of the EPA-only Rx OM-3 product in a large CVOT cannot be extrapolated to other OM-3 products.

Conclusion: Consumers and health care providers need to recognize critical differences between Rx and OM-3 dietary supplements to ensure appropriate use of each OM-3 product.

Keywords: Cardiovascular disease; Dietary supplements; Docosahexaenoic acid; Eicosapentaenoic acid; Fish oils; Hypertriglyceridemia; Icosapent ethyl; Omega-3-fatty acids 


\section{Key Summary Points}

Why provide this review?

In light of recent omega-3 (OM-3) fatty acid cardiovascular outcomes trials (CVOTs), there is a need to understand key differences between available OM-3 products.

\section{What was learned from this review?}

In the statin era, CVOTs of combination OM-3 fatty acids [eicosapentaenoic acid (EPA) and docosahexaenoic acid (DHA)] have not shown reduction in cardiovascular disease (CVD) events.

Recently, the Reduction of Cardiovascular Events with Icosapent Ethyl-Intervention Trial (REDUCE-IT) showed that prescription (Rx)-strength EPA (icosapent ethyl) plus statin resulted in a significantly lower occurrence of CVD events versus placebo plus statin $[17.2 \%$ vs. $22.0 \%$; hazard ratio 0.75 [95\% confidence interval (CI) $0.68-0.83 ; P<0.001]$ in patients at high risk for CVD events; these findings should not be extrapolated to other OM-3 products.

OM-3 dietary supplements are not approved as over-the-counter medications, have no approved clinical indications, and are not subject to the rigorous regulatory standards required for medications; safety issues including variable content of EPA and/or DHA, inconsistencies with labeled quantities, poor product quality, and impurities have been documented.

Among Rx OM-3s, DHA/EPA combination OM-3s should not be substituted for the EPA-only product (icosapent ethyl) as they are not therapeutically equivalent and DHA may raise low-density lipoprotein cholesterol.

\section{INTRODUCTION}

The omega-3 (OM-3) fatty acids eicosapentaenoic acid (EPA) and docosahexaenoic acid (DHA) may have a preventive role in the development and progression of atherosclerotic cardiovascular disease (ASCVD) [1-4]. While both EPA and DHA reduce triglycerides (TG), DHA may raise low-density lipoprotein cholesterol (LDL-C) [5, 6]. Currently available OM-3 products in the US are either prescription (Rx) medications or non-Rx OM-3 dietary supplements (e.g., fish oils) [7]. Although OM-3 dietary supplements are available, there are no Food and Drug Administration (FDA)-approved overthe-counter (OTC) OM-3 medications in the USA. Among available OM-3 products, most contain a combination of DHA and EPA, with the exception of the Rx OM-3 product, icosapent ethyl, which contains only high-purity EPA [8].

Interest in OM-3 products has been renewed because of the recent completion of several large, randomized, placebo-controlled cardiovascular outcomes trials using Rx OM-3 products (CVOTs; Table 1) [9-11]. The impact of combination DHA + EPA [1-g capsule containing $840 \mathrm{mg}$ of OM-3 (460 mg EPA and $380 \mathrm{mg}$ DHA)] was evaluated in two of the recent CVOTs [10, 11]. In A Study of Cardiovascular Events in Diabetes (ASCEND), DHA + EPA was evaluated in patients with diabetes but no known cardiovascular disease (CVD) [10]. The Vitamin D and Omega-3 Trial (VITAL) assessed DHA + EPA as primary CVD and cancer prevention in men aged $\geq 50$ years and women aged $\geq 55$ years [11]. The impact of the EPA-only Rx OM-3 product, icosapent ethyl ( $2 \mathrm{~g}$ twice daily), was evaluated in the Reduction of Cardiovascular Events with Icosapent Ethyl-Intervention Trial (REDUCE-IT) in patients with TG $135-499 \mathrm{mg} / \mathrm{dl}$ despite optimized LDL-C on stable statin therapy [9]. A significant reduction in the primary cardiovascular $(\mathrm{CV})$ outcomes endpoint was demonstrated with the EPA-only $\mathrm{Rx}$ OM-3 in REDUCE-IT, whereas no significant reductions were found with DHA + EPA combination formulations utilized in ASCEND and VITAL 
Table 1 Summary of recent OM-3 CVOTs: ASCEND, VITAL, and REDUCE-IT [9-11]

\begin{tabular}{|c|c|c|c|}
\hline CVOT & $\operatorname{ASCEND}(N=15,480)$ & VITAL $(N=25,871)$ & REDUCE-IT $(N=8179)$ \\
\hline $\begin{array}{r}\text { OM-3 product } \\
\text { (ingredients) }\end{array}$ & $\begin{array}{l}\text { OM-3 combination } \\
\text { (DHA + EPA })\end{array}$ & $\begin{array}{l}\text { OM-3 combination } \\
\text { (DHA + EPA })\end{array}$ & Rx OM-3 (icosapent ethyl [EPA]) \\
\hline Total daily dose & $0.84 \mathrm{~g}^{\mathrm{a}}$ & $0.84 \mathrm{~g}^{\mathrm{a}}$ & $4 \mathrm{~g}$ \\
\hline $\begin{array}{l}\text { Patient } \\
\text { population }\end{array}$ & $\begin{array}{l}\text { Patients with diabetes but no } \\
\text { known CVD, aged } \geq 40 \text { years }\end{array}$ & $\begin{array}{l}\text { Primary prevention } \\
\text { population of men } \\
\text { aged } \geq 50 \text { years and women } \\
\text { aged } \geq 55 \text { years }\end{array}$ & $\begin{array}{l}\text { Patients } \geq 45 \text { years with } \\
\text { established CVD (or } \\
\text { aged } \geq 50 \text { years with diabetes } \\
\text { and at least } 1 \text { additional risk } \\
\text { factor) who had elevated TG } \\
\text { despite optimized LDL-C on } \\
\text { stable statin }\end{array}$ \\
\hline Primary results & $\begin{array}{l}\text { No significant difference in the } \\
\text { incidence of serious vascular } \\
\text { events }{ }^{\text {b }} \text { between group receiving } \\
\text { OM-3 combination versus } \\
\text { placebo }\end{array}$ & $\begin{array}{l}\text { No significant difference in } \\
\text { the incidence of major } \\
\text { cardiovascular events }{ }^{c} \text { or } \\
\text { invasive cancer versus } \\
\text { placebo }\end{array}$ & $\begin{array}{l}\text { The risk of major ischemic events } \\
\text { was significantly lower with } \\
\text { icosapent ethyl versus placebo }\end{array}$ \\
\hline $\begin{array}{l}\text { Significant } \\
\text { improvement } \\
\text { in overall CV } \\
\text { outcomes? }\end{array}$ & No & No & Yes \\
\hline
\end{tabular}

ASCEND A Study of Cardiovascular Events in Diabetes, $C V D$ cardiovascular disease, $D H A$ docosahexaenoic acid, $C V O T$ cardiovascular outcomes trial, EPA eicosapentaenoic acid, $L D L-C$ low-density lipoprotein cholesterol, $O M-3$ omega-3, REDUCE-IT Reduction of Cardiovascular Events with Icosapent Ethyl-Intervention Trial, TG triglycerides, VITAL Vitamin D and Omega-3 Trial

a $380 \mathrm{mg} \mathrm{DHA}$ and $460 \mathrm{mg}$ EPA

b Composite of nonfatal myocardial infarction or stroke (excluding confirmed intracranial hemorrhage), transient ischemic attack, or vascular death excluding intracranial hemorrhage

c Composite of myocardial infarction, stroke, and death from cardiovascular causes

d Composite of cardiovascular death, nonfatal myocardial infarction (including silent myocardial infarction), nonfatal stroke, coronary revascularization, or unstable angina in a time-to-event analysis

[9-11]. These disparate findings from recent OM-3 CVOTs underscore the need to better understand the differences between the various available OM-3 products. Although such differences have health and safety implications for patients, oftentimes neither health care providers nor patients have sufficient knowledge regarding these differences [12-14]. Therefore, health care providers can play an important role in providing clear and accurate information to enhance understanding and enable well-informed decisions regarding OM-3 products.

This narrative review describes therapeutic applications for OM-3 fatty acids, focusing on critical differences between OM-3 dietary supplements and Rx products with an emphasis on the results of recent OM-3 CVOT findings. This article is based on previously conducted studies and does not contain any studies with human participants or animals performed by any of the authors. 


\section{THERAPEUTIC APPLICATIONS FOR OM-3 FATTY ACIDS}

\section{Hypertriglyceridemia: Rx OM-3s}

The FDA-approved Rx OM-3s have been reviewed extensively [15-17] and include various combination products containing both

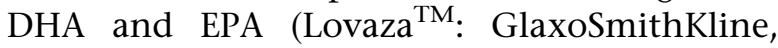
Research Triangle Park, NC, USA; Epanova ${ }^{\mathrm{TM}}$ : AstraZeneca, Wilmington, DE, USA; Omtryg ${ }^{\mathrm{TM}}$ : Trygg Pharma, Arlington, VA, USA; Vascepa ${ }^{\mathrm{TM}}$ : Amarin Pharma, Inc., Bedminster, NJ, USA) [8]. These Rx OM-3 products have clinically proven efficacy and safety and are indicated as an adjunct to dietary interventions to reduce TG in adults with severe hypertriglyceridemia $(\mathrm{TG} \geq 500 \mathrm{mg} / \mathrm{dl}$ ) at $4 \mathrm{~g} /$ day. However, evidence is lacking on the potential benefit in the reduction of pancreatitis risk in this patient population [8, 18-20]. The American Heart Association (AHA) recently issued a science advisory on OM-3s for treatment of hypertriglyceridemia, stating that $\mathrm{Rx} O \mathrm{OM}-3 \mathrm{~s}$, at $4 \mathrm{~g} /$ day, produce TG reductions of approximately $20-30 \%$ in patients with high TG $(200-499 \mathrm{mg} / \mathrm{dl})$ and reductions of $\geq 30 \%$ in those with higher TG $(\geq 500 \mathrm{mg} / \mathrm{dl})$, noting LDL-C increases with DHA-containing products in the latter group [21]. The 2019 AHA advisory concluded that Rx OM-3s (DHA + EPA or EPAonly) are clinically useful for reducing TG after any underlying causes have been addressed and diet and lifestyle strategies implemented, either as monotherapy or an adjunct to other TGlowering therapies [21].

\section{Role in CVD}

The potential impact of OM-3 fatty acid supplementation on CVD risk and outcomes in both primary and secondary prevention populations has been the subject of extensive study [22]. A systematic review of 79 clinical studies of OM-3 dietary supplementation concluded that, based on high-quality evidence, EPA and DHA "do not have important positive or negative effects" on either mortality or CV events. In addition, based on moderate-quality evidence, it was concluded that OM-3s had little or no effect on other measures of CV health in primary or secondary prevention [22]. A 2017 AHA science advisory on OM-3 supplements for prevention of CVD did not recommend OM-3s for prevention of CVD in patients with diabetes mellitus and prediabetes, noting a lack of consensus on the recommendation for patients at high CVD risk, although use in those with established coronary heart disease (e.g., past myocardial infarction) was considered reasonable for potential modest benefit [23]. Also of interest is a meta-analysis of eight randomized clinical studies of patients with hypertension that concluded that fish oil supplements had a statistically significant, but relatively modest effect on blood pressure compared with blood pressure-lowering drugs and thus should not be considered an alternative to guideline-recommended blood pressure-lowering medication for patients with elevated CV risk [24]. Another meta-analysis of ten trials concluded that there was no support for supplementation of OM-3s at approximately $1 \mathrm{~g} /$ day in people with history of coronary heart disease for secondary prevention of CVD events [25]. Despite extensive interest and research, there is a lack of consistent support for OM-3 dietary supplements in $\mathrm{CV}$ risk reduction. As the potential for Rx OM-3s in $\mathrm{CV}$ risk reduction appears promising, it is instructive to review the recently published OM-3 CVOTs.

\section{Key OM-3 CVOTs}

The results of the three most recent, large, randomized, placebo-controlled CVOTs evaluating the impact of OM-3 products are summarized in Table 1 [9-11]. Although the primary CV endpoint was achieved by Rx EPA in REDUCE-IT, the DHA + EPA OM-3 combination formulations did not achieve their primary $\mathrm{CV}$ endpoints in either the VITAL or ASCEND trials. The lack of CV benefits with the DHA + EPA OM-3 combination was a disappointing finding given the promise of earlier reports with dietary supplements in prior clinical trials. In particular, the Gruppo Italiano per lo Studio della Sopravvivenza nell'Infarto miocardico (GISSI)- 
Prevenzione study reported that use of a DHA + EPA OM-3 combination significantly decreased the rate of death, nonfatal myocardial infarction, and stroke in patients who had experienced a heart attack within the prior 3 months [26]. Similarly, among patients with heart failure, the GISSI-HF study showed that a DHA + EPA OM-3 combination reduced allcause mortality and $\mathrm{CV}$ hospital admissions [27]. Potential reasons for the findings of the earlier GISSI study not being borne out in VITAL and ASCEND could be differences in study design and populations, the agents and doses utilized, differences in use of contemporary medical therapy, including statin use, and potential biases in the older studies [22].

In REDUCE-IT, primary CV endpoint events (i.e., CV death, nonfatal myocardial infarction, nonfatal stroke, coronary revascularization, or unstable angina) occurred in $17.2 \%$ of patients in the high-dose Rx EPA (icosapent ethyl) group compared with $22.0 \%$ of patients receiving placebo [hazard ratio 0.75 [95\% confidence interval (CI) 0.68-0.83; $P<0.001$ ] [9]. This corresponded to an absolute difference of $4.8 \%$ (95\% CI 3.1-6.5) between groups and a number needed to treat of 21 (95\% CI 15-33). Based on the results of REDUCE-IT, icosapent ethyl is now also indicated as an adjunct to maximally tolerated statin therapy to reduce the risk of myocardial infarction, stroke, coronary revascularization, and unstable angina requiring hospitalization in adult patients with elevated TG ( $\geq 150 \mathrm{mg} / \mathrm{dL})$ and established CVD or diabetes mellitus and $\geq 2$ additional risk factors for CVD [8]. The potential benefit of an EPA-only $\mathrm{Rx}$ product for $\mathrm{CV}$ risk reduction was first reported in the Japan EPA Lipid Intervention Study (JELIS) [28], which found a significant $19 \%$ relative risk reduction in major coronary events with high-purity EPA plus statin treatment compared with a statin alone in Japanese patients (hazard ratio 0.81; 95\% CI 0.69-0.95; $P=0.011$.

Differences in OM-3 fatty acid composition may also have contributed to disparate CVOT findings. It is possible that, beyond TG lowering, pleiotropic effects of EPA on other lipids/ lipoproteins, inflammation, oxidation, phospholipid membranes, and plaque [2] may have contributed to the CV risk reduction demonstrated in JELIS, REDUCE-IT, and other smaller trials [29]. In light of the recent OM-3 dietary supplement CVOT data [25], the European Medicines Agency Committee for Medicinal Products for Human Use concluded that DHA + EPA combination formulations are not effective in preventing further heart and vascular problems in patients who have had a myocardial infarction and recommended removal of authorization for such use [30]. More recently, the 2019 European Society of Cardiology and European Atherosclerosis Society (ESC/EAS) task force guidelines recommend that, in high-risk patients with TG between 135 and $499 \mathrm{mg} / \mathrm{dl}$ despite statin treatment, the EPA-only OM-3 icosapent ethyl $(2 \times 2$ g/day) be considered in combination with statins [31]. Similarly, in the USA, the 2019 National Lipid Association (NLA) position statement recommends treatment with icosapent ethyl for ASCVD risk reduction for patients aged $\geq 45$ years with clinical ASCVD or $\geq 50$ years with type 2 diabetes and $\geq 1$ additional risk factor who have TG $135-499 \mathrm{mg} / \mathrm{dl}$ on maximally tolerated statin, with or without ezetimibe [32].

Additional factors that may influence CVOT findings include OM-3 dose, definition of primary composite CV endpoint, and study population. The total daily dose of OM-3 was much lower in VITAL and ASCEND $(<1 \mathrm{~g}$ /day total OM-3 per each 1-g capsule) than in REDUCE-IT (4 g/day high-purity Rx EPA). GISSI-Prevenzione and GISSI-HF had positive findings despite relatively low doses of OM-3s ( $\leq 1 \mathrm{~g}$ daily); however, these studies may have had inherent biases, and GISSI-Prevenzione is a much older study, conducted before the modern statin and contemporary medical era. The primary composite $\mathrm{CV}$ endpoint varied between the studies (Table 1, see footnote); for example, in REDUCE-IT, coronary revascularization and unstable angina were included, in addition to $\mathrm{CV}$ death, nonfatal myocardial infarction, and nonfatal stroke. Differences in study populations should also be considered. REDUCE-IT evaluated the impact of high-dose Rx EPA treatment in patients with established ASCVD and in high-risk primary prevention patients 
with elevated TG (135-499 mg/dl) despite optimized LDL-C (41-100 mg/dl) on stable statins. ASCEND and VITAL evaluated patients with diabetes without established ASCVD and a primary prevention population, respectively. Among the positive CVOTs, only REDUCE-IT carries sufficient scientific weight based on current standards of practice, and thus its results may become an important potential consideration in the setting of patients who have or are at high risk for ASCVD. Of note, the treatment group in REDUCE-IT had a higher rate of hospitalization for atrial fibrillation or flutter compared with the control group (3.1\% vs. $2.1 \% ; P=0.004)$. However, those taking icosapent ethyl did have a significantly lower risk of stroke compared with the control group (hazard ratio $0.72 ; 95 \%$ CI $0.55-0.93 ; P=0.01$ ) [9]. A nonsignificant increase in the risk of bleeding, without an increased risk in lifethreatening bleeding, was also observed in the icosapent ethyl group. As such, periodic monitoring is advised for patients taking icosapent ethyl with other medications that may increase the risk for bleeding. Another CVOT of interest is the ongoing STRENGTH trial, which is evaluating an Rx DHA + EPA combination (OM-3 carboxylic acids) in patients with established ASCVD, diabetes with an additional risk factor, or high risk of a future ASCVD event, who are on optimal statin therapy with elevated TG $(\geq 180-<500 \mathrm{mg} / \mathrm{dl})$ [33].

\section{Non-CV Conditions}

Consumers may choose to use OM-3 dietary supplements for potential expectations related to a variety of non-CV conditions, including arthritis, brain health, eye health, maternal-fetal/infant health, and more. Despite the multiple purported benefits, systematic reviews and meta-analyses have found the clinical evidence for OM-3 dietary supplements in these health conditions to be insufficient, inconsistent, or negative [34-39]. For example, a systematic review and meta-analysis of 42 randomized clinical trials of OM-3 dietary supplementation for arthritis noted a moderate benefit among patients with rheumatoid arthritis, but insufficient evidence to determine the effect in other types of arthritis [34]. In terms of brain health, a systematic review of seven clinical studies of OM-3 dietary supplements for Alzheimer's disease (AD) found that cognitive improvement was observed in some cases, particularly in very mild $\mathrm{AD}$; however, the collective evidence was insufficient to support OM-3s in the treatment of AD [35]. Similarly, a metaanalysis of three high-quality randomized controlled trials in cognitively healthy patients $>60$ years of age concluded that OM-3 dietary supplementation did not improve cognitive function [36]. Regarding eye health, a review of dietary interventions for age-related macular degeneration (AMD) found that despite observational studies that suggested reduced risk of progression to advanced $\mathrm{AMD}$, rigorous randomized controlled trials of OM-3s failed to show a decreased risk of advanced AMD development [37]. A large systematic review of OM-3 dietary supplementation [38] examined 143 studies in pregnant or breastfeeding women or infants and found small generally positive effects on birth weight and length of gestation, but concluded that OM-3 dietary supplementation did not have any consistent evidence of effects on peripartum maternal health outcomes or on infant health outcomes such as brain and eye health. Likewise, there was insufficient evidence to draw conclusions regarding the impact of OM-3s on developmental disorders/disabilities in children.

\section{DIFFERENCES BETWEEN MEDICATIONS AND DIETARY SUPPLEMENTS}

Dietary supplements are widely available and popular $[40,41]$; half of US adults and $>70 \%$ of adults aged $\geq 65$ years use supplements according to National Health and Nutrition Examination Survey (NHANES) 2011-2012 data [42]. Dietary supplements are defined as products intended for ingestion to add further nutritional value and/or to supplement the diet including vitamins, minerals, probiotics, fish oils, herbs/botanicals, enzymes, amino acids, and protein powders $[43,44]$. As such, they are 
intended for general consumer health and are not intended to treat any medical condition or disease [43], despite advertising that often implies improvements in clinical conditions.

Patients and health care providers may mistakenly believe that dietary supplements are OTC medications [7]. It is important to educate patients that dietary supplements do not meet the regulatory standards required for OTC drugs and are not approved to treat any disease [43]. In fact, any statement claiming a benefit for a dietary supplement must be accompanied by a disclaimer noting that the stated claim "has not been evaluated by the Food and Drug Administration. This product is not intended to diagnose, treat, cure, or prevent any disease" [43].

\section{Key Differences in Regulatory Requirements}

Important distinctions between dietary supplements compared with OTC and Rx medications are summarized in Table 2 [15, 43, 45-48]. The FDA Dietary Supplement Health and Education Act of 1994 defines dietary supplements very differently from medications [43]. Dietary supplements are not subject to the highly rigorous regulatory standards required for approval of $\mathrm{Rx}$ or OTC medications, do not have the same level of manufacturing and quality control standards, and are not required to establish efficacy or safety prior to marketing [43-45]. In fact, the FDA has no authority to review the safety and effectiveness of dietary supplements before they are marketed and only has the authority to order the removal of dietary supplements from the market if found to be unsafe or to have false or misleading claims [49]. Thus, dietary supplements are considered safe until proven otherwise, whereas medications must not only prove efficacy, but must also prove safety to be made available to the general population. Even when the FDA issues warnings or recalls dietary supplement products, studies have found that very little happens in the way of protecting consumers $[50,51]$.

\section{Safety Considerations}

Patients may view dietary supplements positively and favor taking supplements over medications [52]; however, there have been serious safety concerns with dietary supplements $[50,51,53,54]$. Patients may choose dietary supplements believing these products to be "all natural," yet many dietary supplements have been documented to include undeclared $\mathrm{Rx}$ products or even unapproved drugs [50, 53]. Given the public perception that dietary supplements are safe, it would likely be a surprise to consumers that dietary supplements have been estimated to be implicated in more than 20,000 emergency department visits and 2000 hospitalizations in the US annually [55].

The high prevalence of dietary supplement use among US consumers, along with concerns about safety and misleading claims, prompted the FDA to issue a statement in February 2019 regarding planned efforts to modernize and reform regulation of dietary supplements,

Table 2 Comparison of Rx drugs, OTC drugs, and dietary supplements [15, 43, 45-48]

\begin{tabular}{llll}
\hline Regulatory requirement & Rx drugs & OTC drugs & Dietary supplements \\
\hline Rx from HCP & $\boldsymbol{X}$ & $\boldsymbol{V}$ & $\boldsymbol{x}$ \\
Rigorous FDA oversight & $\boldsymbol{V}$ & $\boldsymbol{x}$ & $\boldsymbol{x}$ \\
FDA approval for marketing & $\boldsymbol{V}$ & $\boldsymbol{V}$ & $\boldsymbol{x}$ \\
Safety and efficacy evidence & $\boldsymbol{V}$ & $\boldsymbol{V}$ & Not allowed \\
Purity and quality control & $\boldsymbol{V}$ & $\boldsymbol{V}$ & \\
FDA approval to treat disease &
\end{tabular}

$F D A$ Food and Drug Administration, $H C P$ health care provider, $O T C$ over the counter, $R x$ prescription

$\boldsymbol{V}$ : required; $\boldsymbol{X}$ : not required 
noting that as the popularity of supplements has grown, so have the number of entities marketing potentially dangerous products or making unproven or misleading claims about the health benefits they may deliver [54].

\section{OM-3 PRODUCT SELECTION: IMPORTANT CONSIDERATIONS}

\section{OM-3 Dietary Supplements}

OM-3 dietary supplements are widely available and popular among consumers [42, 56]. A recent survey of $>700$ patients with CVD who were taking OM-3 products found that the majority of these patients $(86 \%)$ were taking OM-3 dietary supplements without the recommendation/oversight of a health care provider [12]. This is problematic given that OM-3 dietary supplements are subject to many of the same concerns as other dietary supplements, including lack of strict regulation [45]. Multiple issues specific to OM-3 dietary supplements have been reported. For example, variable content of EPA and/or DHA, and inconsistencies with labeled quantities have been documented (Fig. 1) [57-61]. Another issue is poor product quality and purity, including contaminants, cholesterol, saturated fats, and oxidation products (Figs. 1, 2) [57, 59-66]. Unwanted levels of saturated fats (Fig. 1) and oxidation products in excess of safety limits in several top-selling OM3 dietary supplements have been documented (Fig. 2). While the clinical impact of partially oxidized dietary supplements is not established, oxidized lipids have been associated with negative effects on atherogenic lipid CV biomarkers and thus may have implications for patients who have or are at risk for ASCVD [60, 67, 68]. There are data to suggest that contaminants such as polychlorinated biphenyls may counteract the potential benefits of dietary OM-3 intake [69]. Additional, patient-centric concerns with OM-3 dietary supplements include high pill burden, ensuring proper/consistent dose, fishy taste/eructation, label confusion, additional caloric load associated with unwanted lipids/fats in these products, patient compliance/adherence, and cost considerations $[15,17]$.

\section{Rx OM-3 Drugs}

In contrast to fish oils and other OM-3 dietary supplements, $\mathrm{Rx}$ OM-3s are highly purified

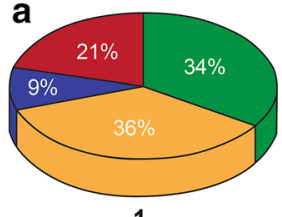

1

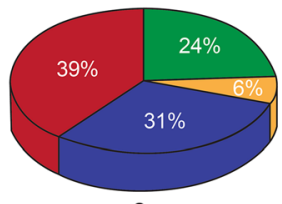

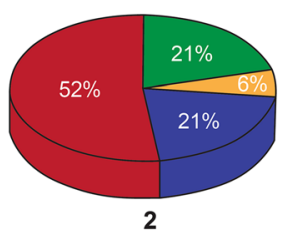

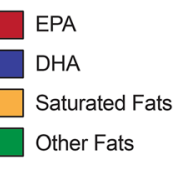

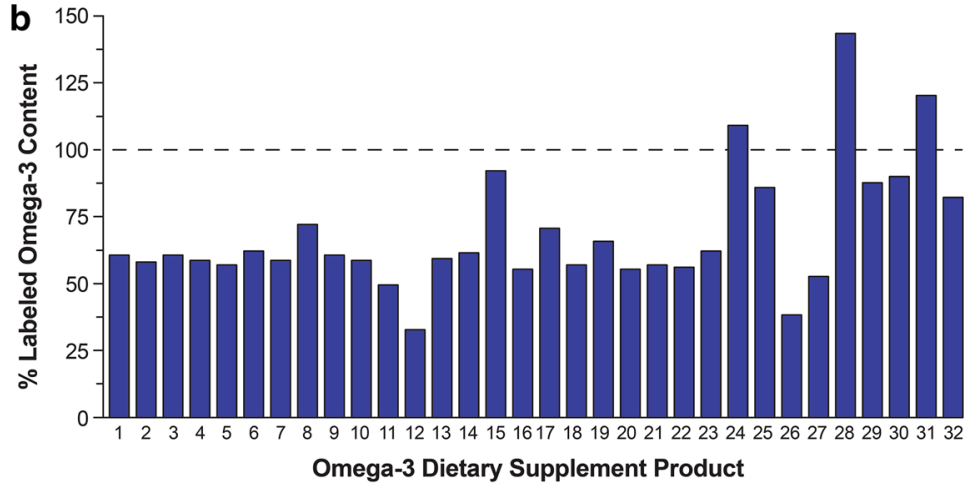

content of widely available fish oil dietary supplements sold in New Zealand, only 3 of 32 products for which OM3 content was measured contained EPA and DHA at levels equal to or higher than that stated on their labels, and the majority contained $<67 \%$ of their stated label content [61]. The dotted line indicates claimed level of OM-3 content. Adapted with permission from Mason 2017 [60] and Albert 2015 [61] 


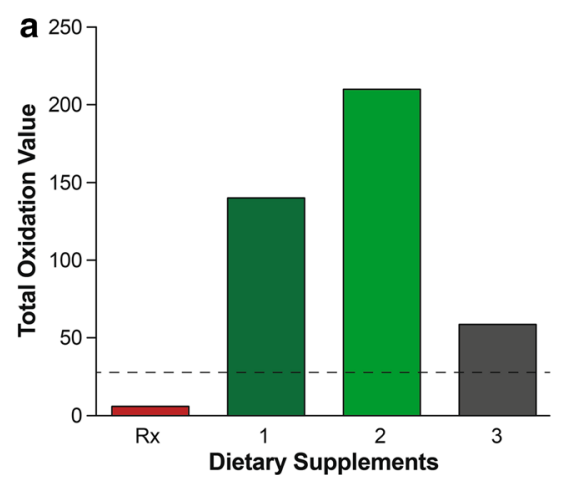

Fig. 2 Oxidation product content in top-selling OM-3 dietary supplements. a In a study of omega-3 dietary supplements available in the US, all three evaluated had oxidation product levels that exceeded recommended levels. The one prescription product evaluated had much lower levels of oxidation products [60]. b In a study of 36

(Fig. 3) [8, 19, 60] and required to meet strict FDA regulatory standards $[17,47]$. Table 3 provides a comparative summary of $\mathrm{Rx}$ OM-3 products (DHA + EPA combinations and the EPA-only product) and OM-3 dietary supplements $[8,9,15,18-20,43,45-48,70]$. In addition to the regulatory rigor required for $\mathrm{Rx}$ OM3 s, the simple fact that a health care provider writes the $\mathrm{Rx}$ and is therefore engaged in the decision-making provides patients with the benefit of medical supervision for their therapy. Of note, the EPA-only $\mathrm{Rx} O \mathrm{OM}-3$, icosapent ethyl, does not raise LDL-C in the absence of concomitant statin therapy and is the only $\mathrm{Rx}$ omega-3 fish oil dietary supplements sold in New Zealand, half of the products exceeded recommended oxidation levels [61]. Dotted lines indicate recommended international thresholds including those recommended by the US Council for Responsible Nutrition. Adapted with permission from Mason 2017 [60] and Albert 2015 [61]

OM-3 product with proven efficacy for both primary and secondary prevention in a CVOT (REDUCE-IT) in the contemporary medical therapy era $[9,71]$.

\section{Substitution}

Patients may be inclined to use OM-3 dietary supplements in lieu of $\mathrm{Rx} \mathrm{OM}-3$ products because of perceptions regarding cost or convenience; however, OM-3 dietary supplements are not considered by the FDA to be equivalent to Rx products and may not be cost-effective as
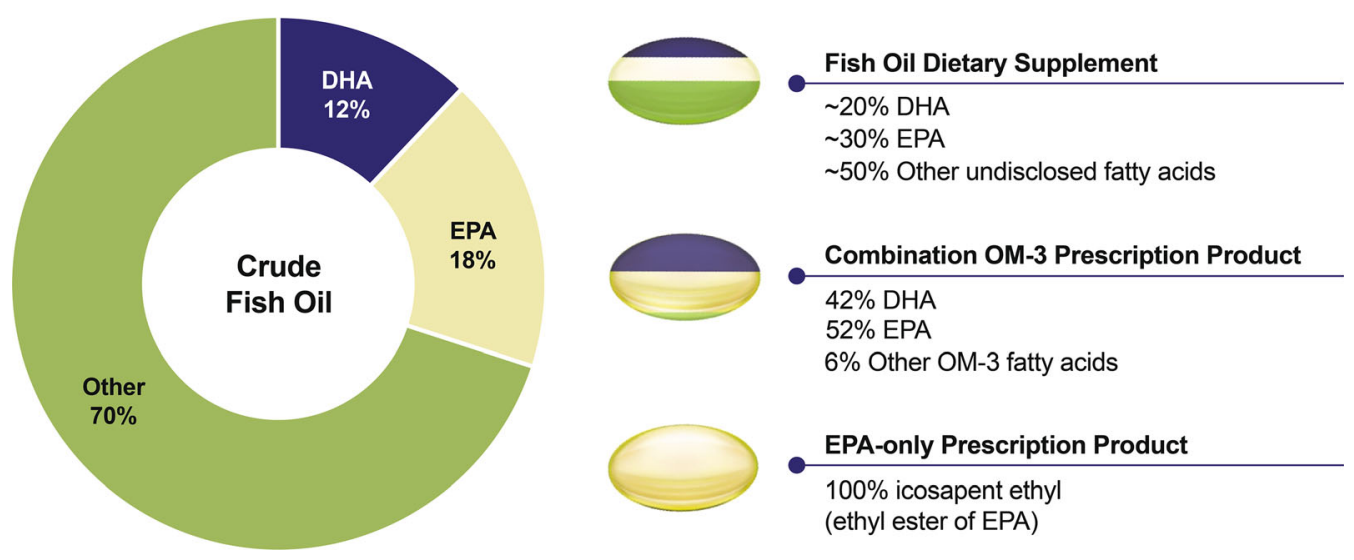

Fig. 3 Differences in purity between fish oil supplements and Rx OM-3s [8, 19]. Composition of dietary supplements can vary greatly between products [60] 
Table 3 Comparison of omega-3 products: $\mathrm{Rx}$ drugs and dietary supplements $[8,9,15,18-20,43,45-48,70]$

\begin{tabular}{|c|c|c|c|}
\hline Features & $\begin{array}{l}\text { Rx } \\
\text { pure } \\
\text { EPA }\end{array}$ & Rx DHA + EPA & $\begin{array}{l}\text { Dietary supplements/OM- } \\
3 \text { combinations }\end{array}$ \\
\hline Highly purified, quality controlled & $\checkmark$ & $\checkmark$ & $\begin{array}{l}\text { May contain unwanted/ } \\
\text { harmful ingredients }\end{array}$ \\
\hline Contains EPA & $\checkmark$ & $\checkmark$ & Usually/highly variable \\
\hline Contains DHA & $x$ & $\checkmark$ & Usually/highly variable \\
\hline Not expected to affect LDL-C & $\checkmark$ & $x$ & $x$ \\
\hline Approved to treat $\mathrm{TG} \geq 500 \mathrm{mg} / \mathrm{dl}$ & $\checkmark$ & $\checkmark$ & $\begin{array}{l}\text { Not FDA approved to treat } \\
\text { any disease or medical } \\
\text { condition }\end{array}$ \\
\hline $\begin{array}{l}\text { Proven CVOT efficacy on background statin } \\
\text { therapy and other contemporary medical } \\
\text { therapy }\end{array}$ & $\checkmark$ & $x$ & $x$ \\
\hline Substitution/equivalence & $\mathrm{N} / \mathrm{A}$ & $\begin{array}{l}\text { Not equivalent to and should } \\
\text { not be substituted for Rx pure } \\
\text { EPA }\end{array}$ & $\begin{array}{l}\text { Not equivalent to and should } \\
\text { not be substituted for Rx }\end{array}$ \\
\hline
\end{tabular}

CVOT cardiovascular outcomes trial, DHA docosahexaenoic acid, EPA eicosapentaenoic acid, FDA Food and Drug Administration, $L D L-C$ low-density lipoprotein cholesterol, $N / A$ not applicable, $R x$ prescription, $T G$ triglycerides

$\checkmark$ : yes, $X:$ no

there is no CV benefit. As previously noted, OM3 dietary supplements are associated with myriad quality and purity concerns, including inconsistent/variable amounts of EPA and DHA [57-59] and presence of unwanted and potentially harmful ingredients [57, 59-66]. Also, it has been estimated that, depending on the DHA + EPA content of a given OM-3 dietary supplement, patients would need to take anywhere from 3 to 112 times the number of supplement doses if attempting to reach Rx doses, corresponding to consumption of an additional 130-140 calories daily [65]. Given these regulatory, safety, and patient-centric considerations, OM-3 dietary supplements should not be substituted for Rx OM-3 products [15].

Among $\mathrm{Rx}$ OM-3 products, DHA + EPA combination $\mathrm{OM}-3 \mathrm{~s}$ are not therapeutically equivalent to pure EPA [70] and therefore should not be substituted for icosapent ethyl. This is particularly important because DHA may raise LDL-C and/or blunt statin LDL-C-lowering effects [15]. Importantly, reduction of CV events observed with the Rx OM-3 icosapent ethyl in REDUCE-IT cannot be extrapolated to other OM-3 products.

\section{NEED FOR A PARADIGM SHIFT}

Consumer self-care is often promoted as empowering. This culture of self-care is partly driven by the idea that individuals have both the right and the intelligence to choose what they put into their bodies; however, there is a prevailing misconception that "natural" products are safer than products manufactured by pharmaceutical companies. This assumption regarding safety is particularly misplaced in the case of fish oil supplements, given the welldocumented issues with consistency of product content and purity. Unfortunately, consumers 
may not be making well-informed decisions regarding OM-3 dietary supplements, with almost $90 \%$ purchasing these supplements without supervision [12]. Also telling is a report that sales of OM-3 dietary supplements rose steadily between 2007 and 2012 (increasing by $>\$ 100$ million each year), despite an overwhelming lack of support for clinical benefits from randomized clinical trials and meta-analyses of OM-3 dietary supplements published around this time frame [72]. Questionable labeling practices such as "pharmaceutical grade" or "clinical grade" and "tested in an FDAapproved laboratory" may lead patients to mistakenly believe there is rigorous regulatory oversight for supplements, on par with that for Rx or OTC medications. Patients who are not aware of documented inconsistencies between labeled versus measured amounts of EPA and DHA in many OM-3 dietary supplements would not realize that labels proclaiming that supplements provide "daily recommended intake for EPA and DHA" may not be reliable.

In addition, consumers may be selecting supplements based on incorrect assumptions regarding their efficacy. While all $\mathrm{Rx}$ OM-3 products are indicated for treatment of severe hypertriglyceridemia [8, 18-20], dietary supplements are not indicated for this or any other medical condition or disease [43]. Along these lines, while Rx EPA recently demonstrated significantly reduced $\mathrm{CV}$ risk in a randomized controlled clinical study [9], these data cannot be generalized to dietary supplements or to other Rx OM-3s because they are not the same. Lack of awareness regarding this evidence gap between various OM-3 products may lead consumers, and even some providers, to choose dietary supplements in cases where specific $\mathrm{Rx}$ OM-3s are warranted.

Pharmacists have an important role in correcting misperceptions regarding OM-3 dietary supplements; however, many consumers do not purchase OM-3 dietary supplements at the pharmacy. Nonetheless, proactive approaches such as asking about dietary supplement use will help raise awareness, particularly among patients who have, or are at risk for, CVD and/ or are taking statins. The American Pharmacists Association has recognized issues with OM-3 dietary supplements, noting that "while omega3 dietary supplements can be an important part of consumer wellness, unlike regulated prescription and OTC drugs, dietary supplements are not required to meet strict FDA drug standards for safety, efficacy, and manufacturing and are not intended to treat serious medical conditions like very high triglycerides" [73]. Likewise, the American Diabetes Association (ADA) guidelines state that evidence does not support a beneficial role for the routine use of OM-3 dietary supplements [74]. On the other hand, the findings of REDUCE-IT have prompted the ADA to update their guidelines to include a recommendation specific to Rx EPA: icosapent ethyl should be considered for CV risk reduction in patients with diabetes and ASCVD or other cardiac risk factors on a statin with controlled LDL-C, but with elevated TG (135-499) [75]. This is in line with updated recommendations from the ESC/EAS and the NLA [31, 32].

In conclusion, consumers and health care providers need to recognize critical differences between Rx OM-3 products and OM-3 dietary supplements to ensure that the optimal plan for each patient's health and wellness is created.

\section{ACKNOWLEDGEMENTS}

Funding. The Rapid Service Fee and the Open Access Fee were funded by Amarin Pharma, Inc. No funding or sponsorship was received for this study.

Medical Writing and/or Editorial Assistance. Medical writing assistance was provided by Kulvinder Katie Singh, PharmD, of Peloton Advantage, LLC, an OPEN Health company, Parsippany, NJ, USA, and funded by Amarin Pharma, Inc., Bedminster, NJ, USA.

Authorship. All named authors meet the International Committee of Medical Journal Editors (ICMJE) criteria for authorship for this article, take responsibility for the integrity of the work as a whole, and have given their approval for this version to be published. 
Disclosures. Daniel E. Hilleman has served on the speakers bureau for Amgen and Amarin and as a consultant for Heron Therapeutics. Barbara S. Wiggins has nothing to disclose. Michael B. Bottorff has served on the speakers bureau for Pfizer and BMS and as a consultant for Medisync.

Compliance with Ethics Guidelines. This article is based on previously conducted studies and does not contain any studies with human participants or animals performed by any of the authors.

Open Access. This article is licensed under a Creative Commons Attribution-NonCommercial 4.0 International License, which permits any non-commercial use, sharing, adaptation, distribution and reproduction in any medium or format, as long as you give appropriate credit to the original author(s) and the source, provide a link to the Creative Commons licence, and indicate if changes were made. The images or other third party material in this article are included in the article's Creative Commons licence, unless indicated otherwise in a credit line to the material. If material is not included in the article's Creative Commons licence and your intended use is not permitted by statutory regulation or exceeds the permitted use, you will need to obtain permission directly from the copyright holder. To view a copy of this licence, visit http://creativecommons.org/licenses/by$\mathrm{nc} / 4.0 /$.

\section{REFERENCES}

1. Borow KM, Nelson JR, Mason RP. Biologic plausibility, cellular effects, and molecular mechanisms of eicosapentaenoic acid (EPA) in atherosclerosis. Atherosclerosis. 2015;242:357-66.

2. Nelson JR, True WS, Le V, Mason RP. Can pleiotropic effects of eicosapentaenoic acid (EPA) impact residual cardiovascular risk? Postgrad Med. 2017; 129:822-7.

3. Endo J, Arita M. Cardioprotective mechanism of omega-3 polyunsaturated fatty acids. J Cardiol. 2016;67:22-7.
4. Mozaffarian D, Wu JH. Omega-3 fatty acids and cardiovascular disease: effects on risk factors, molecular pathways, and clinical events. J Am Coll Cardiol. 2011;58:2047-67.

5. Wei MY, Jacobson TA. Effects of eicosapentaenoic acid versus docosahexaenoic acid on serum lipids: a systematic review and meta-analysis. Curr Atheroscler Rep. 2011;13:474-83.

6. Jacobson TA, Glickstein SB, Rowe JD, Soni PN. Effects of eicosapentaenoic acid and docosahexaenoic acid on low-density lipoprotein cholesterol and other lipids: a review. J Clin Lipidol. 2012;6: $5-18$.

7. Fialkow J. Omega-3 fatty acid formulations in cardiovascular disease: dietary supplements are not substitutes for prescription products. Am J Cardiovasc Drugs. 2016;16:229-39.

8. Vascepa [package insert]. Bedminster, NJ: Amarin Pharma Inc.; 2019.

9. Bhatt DL, Steg G, Miller M, et al. Cardiovascular risk reduction with icosapent ethyl for hypertriglyceridemia. N Engl J Med. 2019;380:11-22.

10. ASCEND Study Collaborative Group, Bowman L, Mafham M, et al. Effects of n-3 fatty acid supplements in diabetes mellitus. N Engl J Med. 2018;379: 1540-50.

11. Manson JE, Cook NR, Lee IM, et al. Marine n-3 fatty acids and prevention of cardiovascular disease and cancer. N Engl J Med. 2019;380:23-32.

12. Hilleman DE, Teply R, Packard KA. Knowledge, perceptions, and patterns of fish oil use in cardiac patients. J Pharm Pract. 2019;1:0897190018824485.

13. Backes JM, Melton BL, Ruisinger JF, Burkhardt CD, Moriarty PM. A comparison of patients' prescribed, self-reported, and actual-intake of supplemental EPA/DHA [poster 161]. National Lipid Association Scientific Sessions, 2016 May 19-20, New Orleans LA; 2016.

14. Hypertriglyceridemia: insights on needs of cardiologists, CV team to reduce residual risk. Cardiology Magazine. 2018. http://www.acc.org/latest-in-cardi ology/articles/2018/04/17/12/42/feature-hypertrig lyceridemia-insights-on-needs-of-cardiologists-cvteam-to-reduce-residual-risk. Accessed May 10, 2018.

15. Hilleman D, Smer A. Prescription omega-3 fatty acid products and dietary supplements are not interchangeable. Manag Care. 2016;1:46B-52B.

16. Bradberry JC, Hilleman DE. Overview of omega-3 fatty acid therapies. Pharm Ther. 2013;38:681-91. 
17. Ito MK. A comparative overview of prescription omega-3 fatty acid products. Pharm Ther. 2015;40: 826-57.

18. Epanova [package insert]. Wilmington, DE: AstraZeneca Pharmaceuticals LP; 2017.

19. Lovaza [package insert]. Research Triangle Park, NC: GlaxoSmithKline; 2015.

20. Omtryg [package insert]. Arlington, VA: Trygg Pharma, Inc.; 2014.

21. Skulas-Ray AC, Wilson PWF, Harris WS, et al. Omega-3 fatty acids for the management of hypertriglyceridemia: a science advisory from the American Heart Association. Circulation. 2019;140: e673-e691

22. Abdelhamid AS, Brown TJ, Brainard JS, et al. Omega-3 fatty acids for the primary and secondary prevention of cardiovascular disease. Cochrane Database Syst Rev. 2018;11:Cd003177.

23. Siscovick DS, Barringer TA, Fretts AM, et al. Omega3 polyunsaturated fatty acid (fish oil) supplementation and the prevention of clinical cardiovascular disease: a science advisory from the American Heart Association. Circulation. 2017;135:e867-84.

24. Campbell F, Dickinson HO, Critchley JA, Ford GA, Bradburn M. A systematic review of fish-oil supplements for the prevention and treatment of hypertension. Eur J Prev Cardiol. 2013;20:107-20.

25. Aung T, Halsey J, Kromhout D, et al. Associations of omega-3 fatty acid supplement use with cardiovascular disease risks: meta-analysis of 10 trials involving 77917 individuals. JAMA Cardiol. 2018;3: 225-34.

26. GISSI Prevenzione Investigators. Dietary supplementation with n-3 polyunsaturated fatty acids and vitamin $\mathrm{E}$ after myocardial infarction: results of the GISSI-Prevenzione trial. Gruppo Italiano per lo Studio della Sopravvivenza nell'Infarto miocardico. Lancet. 1999;354:447-55.

27. Tavazzi L, Maggioni AP, Marchioli R, Barlera S, Franzosi MG, Latini R, Lucci D, Nicolosi GL, Porcu M, Tognoni G; Gissi-HF Investigators. Effect of n-3 polyunsaturated fatty acids in patients with chronic heart failure (the GISSI-HF trial): a randomised, double-blind, placebo-controlled trial. Lancet. 2008;372:1223-30.

28. Yokoyama M, Origasa H, Matsuzaki M, et al. Effects of eicosapentaenoic acid on major coronary events in hypercholesterolaemic patients (JELIS): a randomised open-label, blinded endpoint analysis. Lancet. 2007;369:1090-8.
29. Nosaka K, Miyoshi T, Iwamoto M, et al. Early initiation of eicosapentaenoic acid and statin treatment is associated with better clinical outcomes than statin alone in patients with acute coronary syndromes: 1-year outcomes of a randomized controlled study. Int J Cardiol. 2017;228:173-9.

30. Committee for Medicinal Products for Human Use. Omega-3 fatty acid medicines. 2019. https://www. ema.europa.eu/en/medicines/human/referrals/ome ga-3-fatty-acid-medicines. Accessed Feb 25, 2019.

31. Mach F, Baigent C, Catapano AL, et al. ESC/EAS Guidelines for the management of dyslipidaemias: lipid modification to reduce cardiovascular risk: The Task Force for the management of dyslipidaemias of the European Society of Cardiology (ESC) and European Atherosclerosis Society (EAS). Eur Heart J. 2019;2019:1-78.

32. NLA position on the use of icosapent ethyl in high and very-high risk patients. 2019. https://www. lipid.org/nla/nla-position-use-icosapent-ethylhigh-and-very-high-risk-patients. Accessed Sep 16, 2019.

33. Nicholls SJ, Lincoff AM, Bash D, et al. Assessment of omega-3 carboxylic acids in statin treated patients with high levels of triglycerides and low levels of high density lipoprotein cholesterol: rationale and design of the STRENGTH trial. Clin Cardiol. 2018;41:1281-8.

34. Senftleber NK, Nielsen SM, Andersen JR, et al. Marine oil supplements for arthritis pain: a systematic review and meta-analysis of randomized trials. Nutrients. 2017;9:1.

35. Canhada S, Castro K, Perry IS, Luft VC. Omega-3 fatty acids' supplementation in Alzheimer's disease: a systematic review. Nutr Neurosci. 2018;21: 529-38.

36. Sydenham E, Dangour AD, Lim WS. Omega 3 fatty acid for the prevention of cognitive decline and dementia. Cochrane Database Syst Rev. 2012;20: Cd005379.

37. Evans JR, Lawrenson JG. A review of the evidence for dietary interventions in preventing or slowing the progression of age-related macular degeneration. Ophthalm Physiol Opt. 2014;34:390-6.

38. Newberry SJ, Chung M, Booth $\mathrm{M}$, et al. Omega-3 fatty acids and maternal and child health: an updated systematic review. Evid Rep Technol Assess. 2016;20:1-826.

39. Sunderic M, Robajac D, Gligorijevic N, et al. Is there something fishy about fish oil? Curr Pharm Des. 2019;25:1747-59. 
40. Qato DM, Wilder J, Schumm LP, Gillet V, Alexander GC. Changes in prescription and over-the-counter medication and dietary supplement use among older adults in the United States, 2005 vs 2011. JAMA Intern Med. 2016;176:473-82.

41. Cohen PA. The supplement paradox: negligible benefits, robust consumption. JAMA. 2016;316: 1453-4.

42. Kantor ED, Rehm CD, Du M, White E, Giovannucci EL. Trends in dietary supplement use among US adults from 1999-2012. JAMA. 2016;316:1464-74.

43. Regulatory information: Dietary Supplement Health and Education Act of 1994. Food and Drug Administration Website 2009. http://health.gov/ dietsupp/ch1.htm. Accessed Oct 3, 2019.

44. Cohen PA. Hazards of hindsight-monitoring the safety of nutritional supplements. N Engl J Med. 2014;370:1277-80.

45. Lopez JAG, Ito MK. PLA chapter update: prescription fish oil and Blue Cross of Idaho. LipidSpin. 2010;8:32-4.

46. Dietary supplements: what is safe? American Cancer Society web site 2014. http://www.cancer.org/ acs/groups/cid/documents/webcontent/002385-pdf. pdf. Accessed Oct 3, 2019.

47. Collins N, Tighe AP, Brunton SA, Kris-Etherton PM. Differences between dietary supplement and prescription drug omega-3 fatty acid formulations: a legislative and regulatory perspective. J Am Coll Nutr. 2008;27:659-66.

48. Dietary Supplements. 2018. https://www.fda.gov/ food/dietarysupplements/. Accessed Jan 7, 2019.

49. Dietary supplements: what you need to know. 2017. https://www.fda.gov/food/resourcesforyou/ consumers/ucm109760.htm. Accessed Jan 7, 2019.

50. Tucker J, Fischer T, Upjohn L, Mazzera D, Kumar M. Unapproved pharmaceutical ingredients included in dietary supplements associated with US Food and Drug Administration warnings. JAMA Netw Open. 2018;1:e183337.

51. Harel Z, Harel S, Wald R, Mamdani M, Bell CM. The frequency and characteristics of dietary supplement recalls in the United States. JAMA Intern Med. 2013;173:926-8.

52. Funk RS, Singh RK, Winefield RD, et al. Variability in potency among commercial preparations of berberine. J Diet Suppl. 2018;15:343-51.

53. Tainted products marketed as dietary supplements. 2018. https://www.accessdata.fda.gov/scripts/sda/
sdNavigation.cfm?filter $=\&$ sortColumn $=1 \mathrm{~d} \&$ sd=tain ted_supplements_cder\&displayAll=true. Accessed Feb 25, 2019.

54. Statement from FDA commissioner Scott Gottlieb, M.D., on the agency's new efforts to strengthen regulation of dietary supplements by modernizing and reforming FDA's oversight. 2019. https://www. fda.gov/NewsEvents/Newsroom/PressAnnouncem ents/ucm631065.htm. Accessed Feb 21, 2019.

55. Geller AI, Shehab N, Weidle NJ, et al. Emergency department visits for adverse events related to dietary supplements. N Engl J Med. 2015;373: 1531-40.

56. Clarke TC, Black LI, Stussman BJ, Barnes PM, Nahin RL. Trends in the use of complementary health approaches among adults: United States, 2002-2012. Natl Health Stat Rep. 2015;20:1-16.

57. Shim SM, Santerre CR, Burgess JR, Deardorff DC. Omega-3 fatty acids and total polychlorinated biphenyls in 26 dietary supplements. J Food Sci. 2003;68:2436-40.

58. Kleiner AC, Cladis DP, Santerre CR. A comparison of actual versus stated label amounts of EPA and DHA in commercial omega-3 dietary supplements in the United States. J Sci Food Agric. 2015;95: 1260-7.

59. Ritter JC, Budge SM, Jovica F. Quality analysis of commercial fish oil preparations. J Sci Food Agric. 2013;93:1935-9.

60. Mason RP, Sherratt SCR. Omega-3 fatty acid fish oil dietary supplements contain saturated fats and oxidized lipids that may interfere with their intended biological benefits. Biochem Biophys Res Commun. 2017;483:425-9.

61. Albert BB, Derraik JG, Cameron-Smith D, et al. Fish oil supplements in New Zealand are highly oxidised and do not meet label content of n-3 PUFA. Sci Rep. 2015;5:7928.

62. Tur JA, Bibiloni MM, Sureda A, Pons A. Dietary sources of omega 3 fatty acids: public health risks and benefits. Br J Nutr. 2012;107(Suppl 2):S23-52.

63. Weitz D, Weintraub H, Fisher E, Schwartzbard AZ. Fish oil for the treatment of cardiovascular disease. Cardiol Rev. 2010;18:258-63.

64. Truong P, Johnson C, Gabriel D. Variability of cholesterol and saturated fat content in dietary supplements [abstract P72]. Circulation. 2007;115: e238.

65. Zargar A, Ito MK. Long chain omega-3 dietary supplements: a review of the National Library of 
Medicine Herbal Supplement Database. Metab Syndr Relat Disord. 2011;9:255-71.

66. Jackowski SA, Alvi AZ, Mirajkar A, et al. Oxidation levels of North American over-the-counter n-3 (omega-3) supplements and the influence of supplement formulation and delivery form on evaluating oxidative safety. J Nutr Sci. 2015;4:e30.

67. Nogueira MS, Kessuane MC, Lobo Ladd AA, Lobo Ladd FV, Cogliati B, Castro IA. Effect of long-term ingestion of weakly oxidised flaxseed oil on biomarkers of oxidative stress in LDL-receptor knockout mice. Br J Nutr. 2016;20:1-12.

68. Garcia-Hernandez VM, Gallar M, Sanchez-Soriano J, Micol V, Roche E, Garcia-Garcia E. Effect of omega3 dietary supplements with different oxidation levels in the lipidic profile of women: a randomized controlled trial. Int J Food Sci Nutr. 2013;64: 993-1000.

69. Akesson A, Donat-Vargas C, Berglund M, Glynn A, Wolk A, Kippler M. Dietary exposure to polychlorinated biphenyls and risk of heart failure-a population-based prospective cohort study. Environ Int. 2019;126:1-6.
70. Orange Book: Approved Drug Products with Therapeutic Equivalence Evaluations. US Food and Drug Administration 2017. http://www.accessdata.fda. gov/scripts/cder/ob/. Accessed Oct 3, 2019.

71. Ballantyne CM, Bays HE, Kastelein JJ, et al. Efficacy and safety of eicosapentaenoic acid ethyl ester (AMR101) therapy in statin-treated patients with persistent high triglycerides (from the ANCHOR study). Am J Cardiol. 2012;110:984-92.

72. Grey A, Bolland M. Clinical trial evidence and use of fish oil supplements. JAMA Intern Med. 2014;174:460-2.

73. Agarwal P. APhA convenes stakeholders on appropriate omega-3 fish oil use for VHT. 2015. https:// www.pharmacist.com/apha-convenesstakeholders-appropriate-omega-3-fish-oil-use-vht. Accessed Jan 7, 2019.

74. American Diabetes Association. Standards of medical care in diabetes-2019. Diabetes Care. 2019;41(suppl 1):S1-193.

75. American Diabetes Association. Living standards of medical care in diabetes. 2019. https://care. diabetesjournals.org/living-standards\#2018. Accessed Sep 6, 2019. 